\title{
Memoria crítica y actualizaciones de los debates sobre arte y política en Argentina, a partir de la obra del colectivo La Araña Galponera.
}

Critical Memory and Updates on the Debates about Art and Politics in Argentina Based on the Works of La Araña Galponera Art Collective

\author{
NazARENo Bravo \\ Facultad de Ciencias Políticas y Sociales \\ Universidad Nacional de Cuyo
}

RESUMEN: Este trabajo aborda la actualización de los debates sobre arte y política en relación con la temática del reclamo por verdad, memoria y justicia, asociado a las consecuencias de la represión en Argentina durante la última dictadura cívico-militar. Se busca reconocer las posibilidades de una crítica de la memoria a partir del trabajo del colectivo de arte La Araña Galponera de la provincia de Mendoza.

ABSTRACT: This paper addresses the updating of debates on art and politics in relation to issues such as claim for truth, memory and justice, associated with the consequences of repression in Argentina during its last civic-military dictatorship. It seeks to discover the possibilities of a critical memory based on the works of the art collective La Araña Galponera in Mendoza.

PALABRAS ClAVE: memoria, arte, política, dictadura argentina.

KEYWORDS: memory, art, politics, dictatorship in Argentina

RECIBIDO: 17 de octubre de 2016 • ACEPTADO: 14 de noviembre de 2016 


\section{NAZARENo BRAVO \\ Facultad de Ciencias Políticas y Sociales \\ Universidad Nacional de Cuyo \\ Memoria crítica y actualizaciones de los debates sobre arte y política en Argentina, a partir de la obra del colectivo La Araña Galponera}

\section{Introducción}

Los debates contemporáneos sobre las posibles articulaciones entre arte y política en Argentina se asientan no sólo sobre situaciones recientes, sino sobre ricas experiencias acaecidas en décadas anteriores. Tanto la radicalización política de los años sesenta y mediados de los setenta así como las instancias que fueron posibles en los últimos años de la dictadura cívico-militar (1976-1983), y después del retorno democrático, ofrecen insumos para enmarcar estas discusiones. Un nuevo punto de referencia de este trayecto surge del ciclo de movilizaciones y protestas que se inició a mediados de la década de los noventa en respuesta al impacto del neoliberalismo, que alcanzó, en diciembre de 2001, su punto más alto de ebullición. ${ }^{1}$ La acuciante situación económica y el

1 Los últimos meses de 2001, la crisis económica y las medidas del gobierno en turno enmarcaron una serie de acciones colectivas tendientes a la obtención de alimentos (saqueos a mercados), la exigencia del cumplimiento de los acuerdos entre particulares y entidades bancarias (protestas de ahorristas), el repudio a políticos y funcionarios estatales (cacerolazos en los que surgió la consigna "Que se vayan todos"), el reclamo por fuentes laborales (con los cortes de ruta o piquetes, como estrategia fundamental), entre otros. Los días 19 y 20 en el diciembre de aquel año, violando el 
descreimiento en la dirigencia política fueron paulatinamente replicados a partir de la organización colectiva y el despliegue de innovadoras formas de involucramiento. Esta última etapa es la que sirve de marco para el análisis que se propone.

El reclamo por trabajo, vivienda y alimentos en un contexto de desarticulación de las políticas estatales de asistencia, privatización de los servicios básicos y achicamiento del mercado laboral, atravesaron el territorio nacional y enmarcaron la emergencia de actores políticos con perfiles y prácticas inéditas. La pregunta por las posibilidades y características de los nuevos sujetos políticos y sobre los modos de organización basados en premisas no partidarias reorientó algunas de las discusiones políticas y teóricas desde entonces.

En este contexto, el crecimiento de la protesta y la creación de vías de participación permitieron la aparición y/o el reforzamiento de experiencias colectivas de arte que se sumaron, con sus lenguajes, al debate social. Si bien, el clima de agitación fue perdiendo intensidad durante las gestiones kirchneristas iniciadas en 2003 - cuando se fortaleció nuevamente la legitimidad estatal y disminuyeron los índices de desocupación y pobreza-, es posible afirmar que muchas de las inquietudes que orientaron las instancias de involucramiento político y artístico se mantuvieron vigentes; inquietudes que comenzaron a reforzarse en diciembre de 2015, ya bajo la gestión liberal ortodoxa de la alianza Cambiemos.

Uno de los temas que vinculó a colectivos de arte con agrupaciones políticas antes, durante y después de 2001 es el reclamo de verdad y justicia por las violaciones a los derechos humanos, perpetradas por la última dictadura. Como ha sido señalado, un ámbito puntual en el que se establecieron relaciones fluidas entre trabajos artísticos y perfiles militantes renovados, desde mediados de los noventa, fueron los escraches. Estas manifestaciones de denuncia en los domicilios de los represores, al apostar por la condena social, cuestionaron las limitaciones legales

estado de sitio que decretó el expresidente F. de la Rua, miles de personas salieron a las calles en todo el país y se enfrentaron con las fuerzas de seguridad. Aquellas jornadas dejaron como saldo al menos 38 víctimas de la represión policial, la renuncia del presidente y la unión circunstancial de sectores movilizados pertenecientes a distintos estratos sociales. 
existentes para juzgar a los responsables. (Giunta 2009; González 2013; Longoni 2013).

Con base en esta referencia es posible, en primer lugar, orientar las discusiones sobre la vitalidad de esas articulaciones entre arte y política habilitadas hacia la problemática de la memoria y los derechos humanos. En segundo término, se puede reconocer dichos procesos en obras elaboradas específicamente para el circuito artístico; esto es, trascender la protesta social como ámbito exclusivo de estos entrecruzamientos. Este trabajo busca destacar una serie de propuestas de arte ocurridas recientemente en la provincia de Mendoza, como modo de obtener elementos para dicho debate. Con este objetivo, se tendrán en cuenta dos exposiciones recientes del colectivo de arte La Araña Galponera (LAG): Ejercicio 1972 (2015) y Borrar, quemar, descubrir (2016) como bases para la discusión de una "crítica de la memoria" postulada por la intelectual chilena Nelly Richard (2010). ${ }^{2}$

Reactualización de los debates sobre arte y política. El caso de La Araña Galponera

Como se dijo, existe coincidencia en ubicar la segunda mitad de la década de 1990 como el punto de partida de un periodo de protestas, organización y confluencia de colectivos de participación y de producción artística.

Dos coyunturas son cruciales en la aparición, la multiplicación y la vitalidad de grupos de arte en la calle vinculados a nuevos movimientos sociales surgidos en la Argentina de la última década. La primera, a mediados de la década del 90, es el surgimiento de H.I.J.O.S. [...] Los comienzos de dos grupos que continúan trabajando, el GAC [Grupo de Arte Callejero] y Etcétera... están fuertemente emparentados con la elaboración y realización de los escraches, la modalidad de acción directa que impulsan los H.I.J.O.S. para señalar la impunidad de los represores y generar condena social (Longoni 2013: 93).

2 Además de las observaciones realizadas en las muestras, se realizó una serie de entrevistas a los integrantes de La Araña Galponera entre marzo y julio de 2016, como parte de una propuesta de investigación aún en curso. 
El surgimiento de agrupaciones de H.I.J.O.S. (en la que confluyeron hijos e hijas de desaparecidos, ex presos políticos, fusilados y exiliados), en Argentina y en otros países de Latinoamérica y Europa a partir 1995, graficó la renovación generacional del activismo por verdad, memoria y justicia. ${ }^{3}$ Los escraches lograron un enorme impacto social que se basó, en muchas ocasiones, en la apelación a estrategias de arte para su concreción.

La segunda coyuntura, al calor de la revuelta de diciembre de 2001, incluye una cantidad notable de grupos de artistas plásticos, cineastas, videastas, poetas, periodistas alternativos, pensadores y activistas sociales, que inventaron nuevas formas de intervención vinculadas a los acontecimientos y movimientos sociales con la expectativa de cambiar la existencia en Argentina: asambleas populares, piquetes, fábricas recuperadas por sus trabajadores, movimiento de desocupados, clubes de trueque, etcétera. El aprovechamiento subversivo de los circuitos masivos y la generación de dispositivos de comunicación alternativa son condiciones que son patrimonio común de las nuevas modalidades de la protesta (Longoni 2013: 93).

Debe valorarse que muchas de las expresiones de esa protesta no fueron leídas como políticas ya que, justamente, rompían con parámetros establecidos en ese terreno. La no apelación a estructuras partidarias o sindicales como ámbitos en los cuales encausar los reclamos, sumado al rechazo a "los políticos de siempre" de gran parte de las nuevas organizaciones, orientaron el análisis de muchas de aquellas experiencias a actos de protesta o estrategias de sobrevivencia.

Algo muy similar ocurrió en el ámbito artístico con las intervenciones de arte que se produjeron durante aquel ciclo. "Tanto la señalética urbana del GAC como las perfomances de Etcétera... quedaron en principio completamente invisibles para el campo artístico como 'acciones de arte', y en cambio proporcionaron identidad y visibilidad a los escraches" (Longoni 2013: 93).

3 Las organizaciones de derechos humanos de Argentina denuncian la existencia de 30000 casos de desaparición de personas, 10000 presos políticos y 2 millones de exiliados durante el último gobierno de facto. 
Con diversidad de estrategias y posibilidades marcadas por el contexto de la época, el arte ensayó modos de involucrarse en un proceso de militancias de nuevo corte. Ese "arte activista" (Felshin 1994: 74) pudo ser reconocido, en principio, como un profundo visibilizador de procesos y reclamos elaborados por sectores excluidos. Además, es necesario apuntar que esta vocación participativa y cuestionadora del orden impuesto se expresó también en la experimentación de lenguajes estéticos y preguntas que conmovieron al propio campo artístico. Es interesante observar cómo, sin desconocer las particularidades del ámbito político y las del artístico, se produjeron aportes cruzados que lograron dar legitimidad y reconocimiento a experiencias subalternas al interior de esos ámbitos, más allá de las definiciones conceptuales sugeridas por los estudios científicos a posteriori.

Pero basar las discusiones sobre la relación entre arte y política en una de sus expresiones (fundamentalmente callejeras, como marchas, escraches, cacerolazos o piquetes) puede ser limitante. Esto sucede porque no permite la observancia de procesos y producciones que se asientan en ese mismo entrecruzamiento, sin que necesariamente formen parte de acciones en la vía pública, asunto que será ejemplificado empleando el análisis que propondremos de las muestras de La Araña Galponera.

El trayecto que el colectivo inició en 2007, en la provincia de Mendoza, posee numerosos puntos en común con las experiencias "activistas" y callejeras anteriormente mencionadas, aunque también incluye destacadas producciones pensadas específicamente para el circuito artístico. Entonces, pensar al colectivo dentro de esa oleada de participación y discusión, asociada genéricamente a la crisis de 2001, puede restringir la mirada sobre su obra, tal como lo reconocen sus integrantes en una de las entrevistas realizadas: ${ }^{4}$

Es difícil definir qué hace La Araña en pocas palabras y, seguramente, en comparación con otros artistas, pueda ser identificado con la idea de crítica social. Pero no nos reconocemos solamente en esa mirada. Se piensan que por dedicarte a "arte y política", renuncias a la experimen-

4 Todas las declaraciones de los integrantes del colectivo de arte fueron tomadas de entrevistas realizadas por el autor entre marzo y julio de 2016. 
tación de lenguajes, una cuestión a la que se le da mucho valor en el campo de las artes. Y nosotros también experimentamos con el lenguaje. Lo que pasa es que no lo hacemos como único objetivo o como un fin en sí mismo.

El desafío, en todo caso, es lograr una valoración de sus producciones que no quede limitada a un "aporte" a la movilización, sino que se asiente en la observación crítica de las "estrategias estéticas para poner a circular debates, discursos, mensajes, sueños. Porque lo político está en decir lo que se necesita decir en cada contexto, sea una marcha, un museo o una galería", según afirman sus integrantes.

La Araña Galponera surge cuando el ambiente político ya no estaba hegemonizado en la crisis y los reclamos. Ese sitio entonces era ocupado por los debates entre el kirchnerismo y las oposiciones de derecha e izquierda. Algunos de sus integrantes venían compartiendo espacios de formación entre 1999, cuando ingresaron a la Facultad de Artes y Diseño de la Universidad Nacional de Cuyo (UNCUYo), y 2005. Quienes integrarían La Araña ya compartían discusiones y actividades, aunque aún sin un nombre común. Es decir que la crisis de 2001 y lo que vino después los encontró en pleno debate sobre las formas de transmitir y practicar el arte y las movilizaciones estudiantiles que confluían con organizaciones de trabajadores y de derechos humanos.

Algunos de los nudos temáticos que han sido abordados por La Araña Galponera poseen un anclaje concreto en problemáticas actuales y, en muchos casos, con fuerte raigambre local. Esa lectura de la realidad provincial ha quedado plasmada en algunas de las intervenciones y obras que el colectivo ha realizado en torno a situaciones conflictivas - los intentos de instalar la mega minería, el asesinato de jóvenes de sectores populares a manos de la policía o la multiplicación de controles en la vía pública - , como respuesta a la inseguridad asociada al delito común.

Finalmente, también deben tomarse en cuenta las características de su acción colectiva - la manera de organizarse, de establecer relaciones con distintos actores, de financiarse-, deudora del espíritu asambleario, horizontal y autogestivo que logró encaramarse como opción para organizaciones políticas y movimientos sociales en la etapa contem- 
poránea. Dichos aspectos están íntimamente relacionados con el modo de producción de las obras, de lo que se desprende la importancia de considerarlas en sintonía con sus definiciones estéticas y elaboraciones discursivas.

Esta coincidencia en modos organizativos y perspectivas de la realidad, que lograron colectivos políticos y de arte, dio pie a debates sobre esas relaciones. Andrea Giunta subrayaba en 2009 que "[...] todas las formas de organización colectiva se intensificaron inmediatamente después de la crisis y, en ocasiones, se vincularon en un mismo espacio y bajo un mismo lema señalando un momento extraordinario de investigación sobre las redes de sociabilidad" (Giunta 2009: 17). En el caso de La Araña Galponera, la articulación con organizaciones sociales y políticas se vuelve posible en el contexto cotidiano de la Casita Colectiva - lugar que comparte con otras agrupaciones - y con los organismos de derechos humanos de la provincia, principalmente H.I.J.O.S., en Mendoza.

En otras palabras, la trayectoria de este colectivo permite abordar problemáticas y discusiones de la etapa de implosión institucional y profundización de la protesta de 2001, y observar una experiencia que, a diferencia de otras en las que se basaron los trabajos sobre arte activista, consiguió sostenerse en el tiempo, así como instalar discusiones más allá de la protesta social.

\section{Memoria e identidad como ejes de acción política}

En Argentina en particular y en los países del Cono Sur en general, la temática de los derechos humanos violados por el Estado en las décadas de los setenta y ochenta del siglo pasado así como la de la importancia de la memoria sobre ese pasado resultaron nudos centrales para la reconstrucción democrática postdictadura. Nelly Richard destaca la asociación entre memoria e identidad, en términos de lazos forjados en comunidad, de vínculos que garantizan acuerdos que permiten un entendimiento básico y que se materializan en producciones y procesos: "el sustrato identitario de la memoria social entendida como vínculo de pertenencia y comunidad se expresa a través de imágenes, símbolos, 
narraciones y escenas cuyos lenguajes figurativos, en un paisaje de pos dictadura, rondan alrededor de las huellas y carencias de lo que falta" (Richard 2010: 15).

La posibilidad de postular un(os) nosotros-as con capacidad de acción y reflexión depende de esos lazos comunitarios, resultantes de pugnas, imposiciones y consensos que atraviesan las relaciones sociales. Las identidades colectivas, jamás definitivas ni homogéneas pero lo suficientemente soldadas como para permitir un reconocimiento compartido, encuentran en la mirada sobre el pasado uno de sus pilares fundamentales. Y si en ese pasado lo que ocurrió fue un genocidio (Feirstein 2012), es entendible que parte de las producciones busquen abordarlo desde diversos registros. Se refuerza así la centralidad que poseen las significaciones del pasado en el proceso identitario.

Aunque parecen invocar un origen en un pasado histórico en el cual continúan en correspondencia, en realidad las identidades tienen que ver con las cuestiones referidas al uso de los recursos de la historia, la lengua y la cultura en el proceso de devenir y no de ser; no "quiénes somos" o "de dónde venimos" sino en qué podríamos convertirnos, cómo nos han representado y cómo atañe ello al modo como podríamos representarnos. Las identidades, en consecuencia, se constituyen dentro de la representación y no fuera de ella (Hall 1996: 17-18).

Entonces, no se desentraña una identidad "verdadera" que proviene de un pasado compartido, más bien se elaboran visiones del pasado que son posibles en el presente y que cubren todo el proceso identitario. De ahí la condición política de la identidad, porque habilita modos de percepción que permiten ubicarnos en tiempo y espacio, actuar, narrarnos una correspondencia entre pasado y presente con la cual proyectar posibles futuros. Usando estas elaboraciones colectivas, se establecen márgenes (dinámicos, nunca eternos ni naturales) y posibilidades (históricas) para significar el sentido de, por ejemplo, "bien común", "Estado", "autoridad", "democracia" o "justicia”, sólo por nombrar algunas palabras.

En contextos de una extrema criticidad, como es el despliegue de un plan sistemático de represión, las dificultades para su elaboración co- 
lectiva son variadas. La necesidad de fundar y sostener lazos comunitarios que incorporen los hechos traumáticos a partir de su discusión y de la búsqueda de mecanismos para abordarlos se basan, primeramente, en aceptar su ocurrencia. Activismo político y estrategias de arte fueron, y son, bases para elaboraciones identitarias que no niegan el extendido proyecto de destrucción de lazos comunitarios que desplegó la última dictadura, sino que ensayan maneras de representarlo, de hacer circular debates que mantengan vigente su discusión. En este punto, vale remarcar nuevamente que los vínculos entre artistas y militantes de derechos humanos en Argentina poseen una extensa trayectoria, ejemplificada en momentos paradigmáticos como los que provocó el Siluetazo en los últimos meses de la dictadura (Longoni y Bruzzone 2008).

\section{Un acercamiento a la crítica de la memoria}

Nelly Richard señala la necesidad de una crítica de la memoria que refute tanto el olvido como aquellas versiones del pasado que lo vuelven inamovible, fijado para siempre, neutralizado; apuesta oficial de la transición democrática chilena "en función del ideal reconciliatorio del consenso" (Richard 2010: 17). ${ }^{5}$

Se trata de procesos que permiten una rememoración. En ellos prevalecen las preguntas abiertas por encima de las respuestas tajantes; el señalamiento de lo omitido sobre las certezas de lo registrado; miradas divergentes en vez de visiones oficializadas del pasado.

Así como la entiendo, la "crítica de la memoria" no sólo debe encargarse de revisar y discutir las huellas del pasado archivado por la historia

5 Reconciliación que, para el caso chileno, no incluía inicialmente condenas por los crímenes de Estado, sino más bien una vuelta de página como fórmula para cerrar el tema en vistas del futuro. En este punto, conviene remarcar las diferencias entre las transiciones chilena y argentina: en Chile la vuelta democrática estuvo mucho más condicionada por el poder militar (con A. Pinochet en el cargo de "senador vitalicio" como ejemplo paradigmático) y el movimiento de derechos humanos de aquel país no logró la trascendencia política que obtuvo en Argentina. Puede decirse que, en el caso argentino, los intentos de imponer una reconciliación sin justicia fueron revertidos paulatinamente por la movilización social aglutinada por las organizaciones de derechos humanos. 
para reanimar contra interpretaciones de lo sucedido y lo relatado que se mantengan refractarias a la canonización de los hechos y sus versiones legitimadas. Le incumbe también a la "crítica de la memoria" descifrar los silenciamientos, las reservas, las omisiones y las negaciones, los lapsus que desfiguran o socavan la representación histórica con su pasado turbulentamente ubicado en el fuera-de-archivo de las narrativas institucionales y, también, de las disciplinas académicas (Richard 2010:18).

Podría decirse que esta "crítica de la memoria" es un programa de intervención y una perspectiva para analizar prácticas sociales y simbolizaciones, que se caracteriza por su desconfianza en las versiones oficializadas ("usos del recuerdo fijados, canonizaciones") y el planteamiento de tareas concretas ("reanimar contra interpretaciones, descifrar silenciamientos").

La elección de La Araña Galponera como caso para este trabajo además de permitir el desarrollo de esa táctica de análisis presente en la "crítica de la memoria" que propone Richard, también reside en las búsquedas estéticas del colectivo que, en varios sentidos, parecen aplicar sus preceptos a modo de guía de intervención.

Desde que surgimos como grupo, pero antes también, hemos participado en las marchas que se hacen en rememoración y repudio al último golpe de Estado del 76 o en actividades relacionadas. En ese contexto, como artistas, nos propusimos no sacarla de taquito, o sea, no apelar siempre a los recursos que ya están consolidados. Queremos superar un lenguaje basado en las botas, la sangre y las siluetas, que fue fundamental en su momento pero que necesariamente hay que trascender. Todos los años pensamos qué hacer y cómo presentarlo en cada lugar, una marcha o una muestra. Es donde menos ortodoxos hemos sido, buscando cómo relacionarlo con situaciones de hoy, como el "gatillo fácil", planteando un contrapunto con el discurso de la seguridad, que por momentos tiñe todo y esconde nuevas versiones del autoritarismo (La Araña Galponera).

A continuación, se describirán resumidamente dos muestras grupales de La Araña Galponera para, posteriormente, analizarlas a la luz de la propuesta de Richard. 
Ejercicio 1972 (Espacio de Arte de la Universidad Tecnológica Nacional Regional Mendoza, abril de 2015)

En marzo de 2015, los integrantes de La Araña Galponera inauguraron la muestra Ejercicio 1972 en el espacio de arte que posee la Universidad Tecnológica Nacional en Mendoza. En sintonía con las actividades de rememoración del golpe de Estado de 1976, el colectivo inició un proceso de investigación sobre la vida política de esa facultad previa al último golpe.

La necesidad de representar el pasado se nutre de experiencias en primera persona, que nunca son del todo individuales porque ocurrieron a miles de personas, pero, sobre todo, porque condicionaron desde entonces a toda la sociedad. La lectura de materiales y la realización de entrevistas a ex estudiantes de la Universidad Tecnológica Nacional (UTN) condujeron a la elaboración de un conjunto de obras que apuntalaron elaboraciones divergentes del pasado vinculado a la represión

Esas memorias compartidas nos llevaron a buscar la manera de multiplicar ese hecho, de servir de enlace entre ese pasado y la actualidad. De concebir a la memoria no sólo como un recuerdo sino como el ejercicio de no olvidar, como acción, como verbo. Y al mismo tiempo, el ejercicio de reconstrucción de la ausencia, del vacío, de lo que no está (La Araña Galponera 2015).

Se presentaron tres pizarras escolares de color negro en las que se podía leer un conjunto de letras en tiza blanca, aparentemente inconexas, a la manera de una "sopa de letras" (imágenes 1, 2 y 3). Allí, los espectadores fueron invitados a ubicar y marcar los nombres de "cómplices de la dictadura que habrían confeccionado listas negras en la UTN". ${ }^{6}$ En otras pizarras, los espectadores localizaron "reivindicaciones por las que lucharon nuestros compañeros de la UTN desde 1972" y "los nombres de los/as estudiantes desaparecidos/as de la UTN". ${ }^{8}$

6 Apellidos de cómplices de la represión en la UTN: Puleo, Amstutz, Seijo, Burlot, Lucas, Guiñazú.

7 Reivindicaciones del movimiento estudiantil: "planes de estudio", "solidaridad", "latinoamericana", "cátedras paralelas", "libertad”, "horario nocturno", "revolución”, "apuntes", "trabajo", "unidad obrera", "universidad".

8 Estudiantes asesinados y desaparecidos de la UTN: G.L. Tenembaum, Mario Camín,Escamez Ruarte, J.J.Galamba,M. Susso, J.A.Chizu, J.A. Hidalgo, O. Rosales, I. E. Fresno 

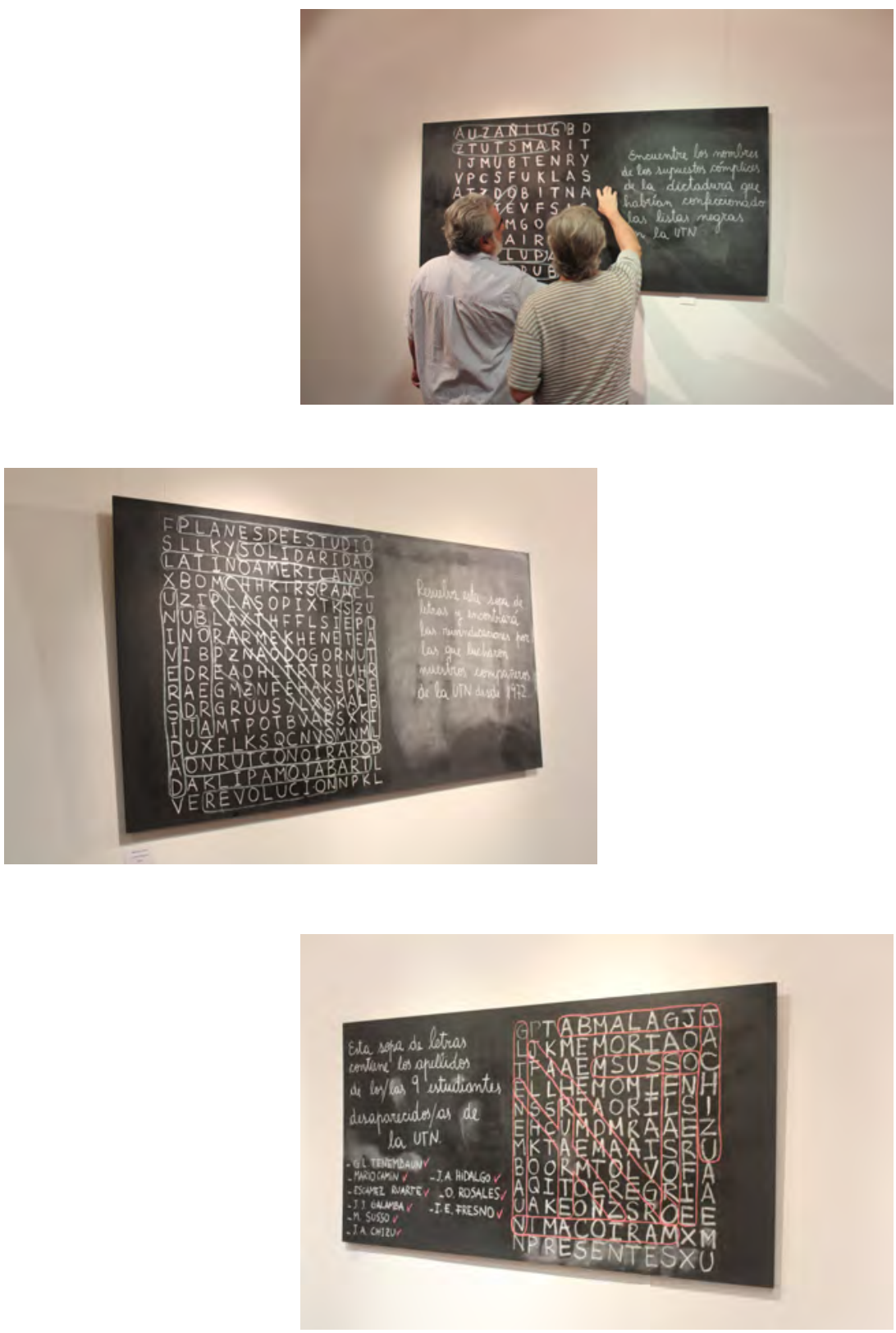

IMÁGENES 1,2 y 3. Sopas de letras presentadas en la muestra y resueltas por el público asistente. Fotografías de Macarena Espinosa. 
La muestra se complementó con textos que replicaban, en su forma y estilo, los panfletos y declaraciones públicas de las agrupaciones políticas que habían tenido un profundo trabajo militante antes del golpe: "Ante las amenazas", "Compañeros" y "La UTN puede desaparecer" (imágenes 4 y 5). Cada una de estas "reconstrucciones mnemónicas" se repetía un par de veces, una al lado de la otra. Sin embargo, ninguna podía leerse de forma completa, ya que palabras o frases enteras habían sido recortadas, dejando un vacío en su lugar. En este caso, para poder reconstruir los mensajes, los espectadores debían complementar las partes faltantes tomando como referencia los carteles contiguos o ensayando posibles complementos.
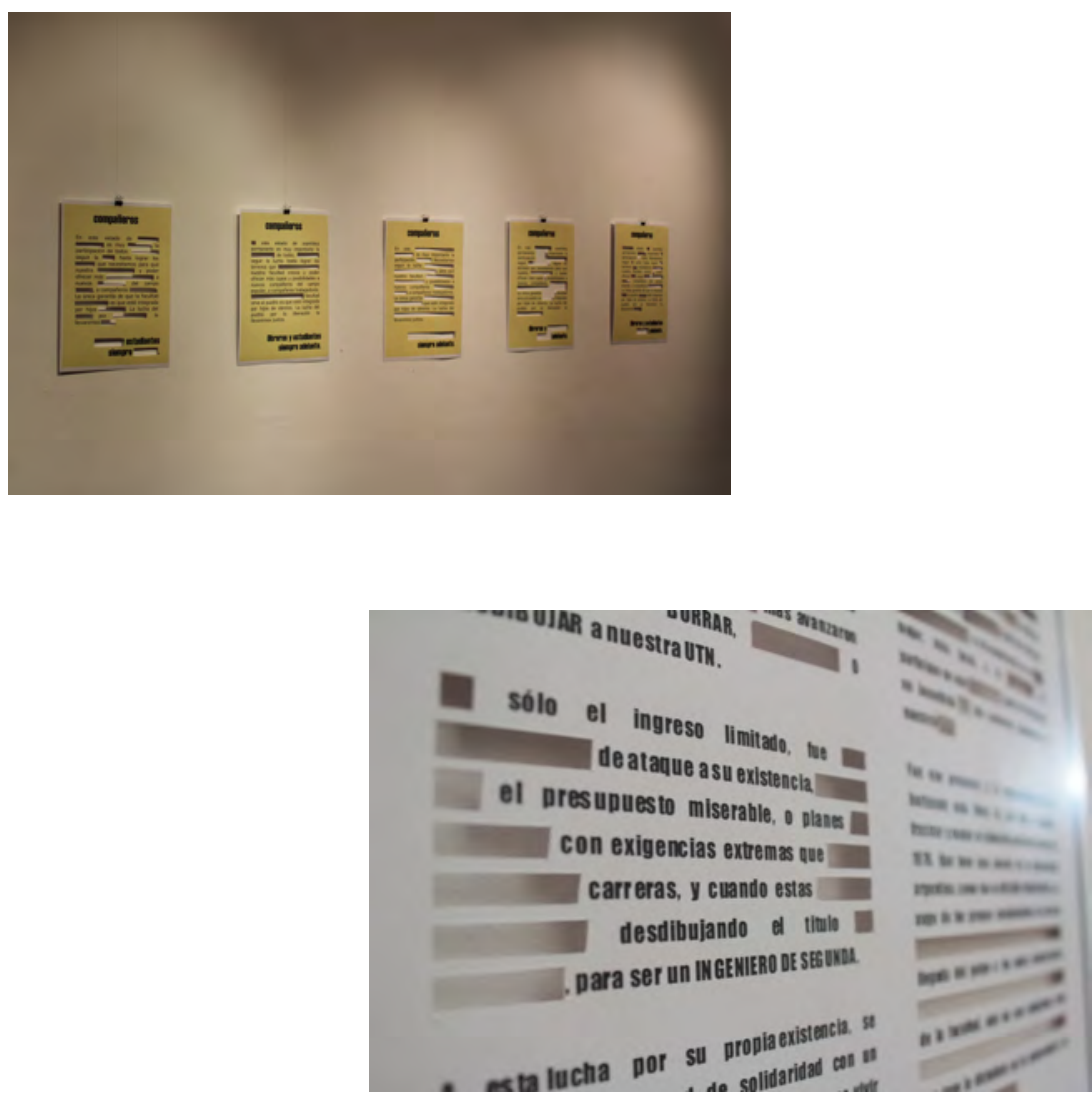

IMÁGENES 4 y 5 . Las proclamas reconstruidas por los ex estudiantes, intervenidas por La Araña Galponera. Fotografías de Macarena Espinosa. 
Borrar, quemar, descubrir

(Casita Colectiva, abril de 2016)

Los trabajos que integraron esta muestra también fueron elaborados en forma conjunta por los integrantes de La Araña y expuestos en abril de 2016 en el salón de usos múltiples de la Casita Colectiva, espacio que el grupo promueve como sala de artes. Días después de las actividades y la movilización por los 40 años del golpe - en la que el colectivo participó como lo viene haciendo desde su formación - , la muestra propuso una serie de trabajos que se instalan en el tema de la memoria y cuestionan su alcance y las garantías de su sostenimiento.

Por un lado, obras basadas en casos paradigmáticos de violencia estatal o paraestatal: un retrato de Julio López (imagen 6), ${ }^{9}$ realizado a lápiz y que pareciera en proceso de ser borrado, ya que, además de no estar completo, incluye restos de goma de borrar que muestran recientes supresiones. Asimismo, imágenes de jóvenes asesinados por la policía ${ }^{10}$ y víctimas de feminicidio en Mendoza ${ }^{11}$ fueron plasmadas sobre gomas de borrar (imagen 7).

Por otro lado, una secuencia graficada con restos de distintos tamaños de gomas de borrar indica comienzos y recomienzos que se encadenan de manera continua (imagen 8). Este trabajo quedó emparentado con una instalación de audio y video proyectado sobre una de las paredes del salón, en el que podía verse a un grupo de personas con los rostros cubiertos - los propios artistas - frente a la Casa de Gobierno provincial alrededor de una fogata hecha, también, con ese útil escolar.

Entre estos trabajos destacó, por su tamaño y confección, una reproducción pintada del frente del edificio del (ex Centro Clandestino de Detención) D2, cubierta con una película de grafito: una opacidad

9 Julio López es un militante que permaneció secuestrado durante la dictadura militar y que, en calidad de testigo durante uno de los primeros juicios por delitos de lesa humanidad, fue nuevamente secuestrado y desaparecido en 2006, en plena democracia. La causa de su segunda desaparición arroja escasísimos avances, y marca las limitaciones del sistema para democratizar a las fuerzas de seguridad.

10 Se trata de los rostros de Ezequiel Torres (22 años) y Leonardo Rodríguez (30 años), muertos por agentes de la policía de Mendoza en noviembre de 2012 y 2015 , respectivamente.

11 Soledad Olivera (31 años) y Johana Chacón (13 años), desaparecidas desde 2011 y 2012, respectivamente. 


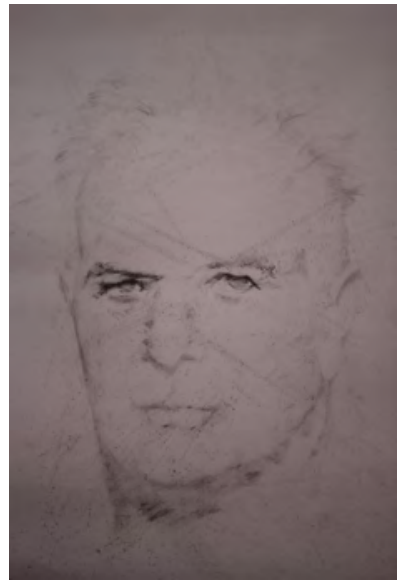

IMAGEN 6: Retrato de Julio López, dos veces secuestrado y desaparecido. Fotografía de Andrés Guerci.

IMAGEN 7: Víctimas de la violencia policial y machista en democracia. Fotografía de Mariela Guerci.
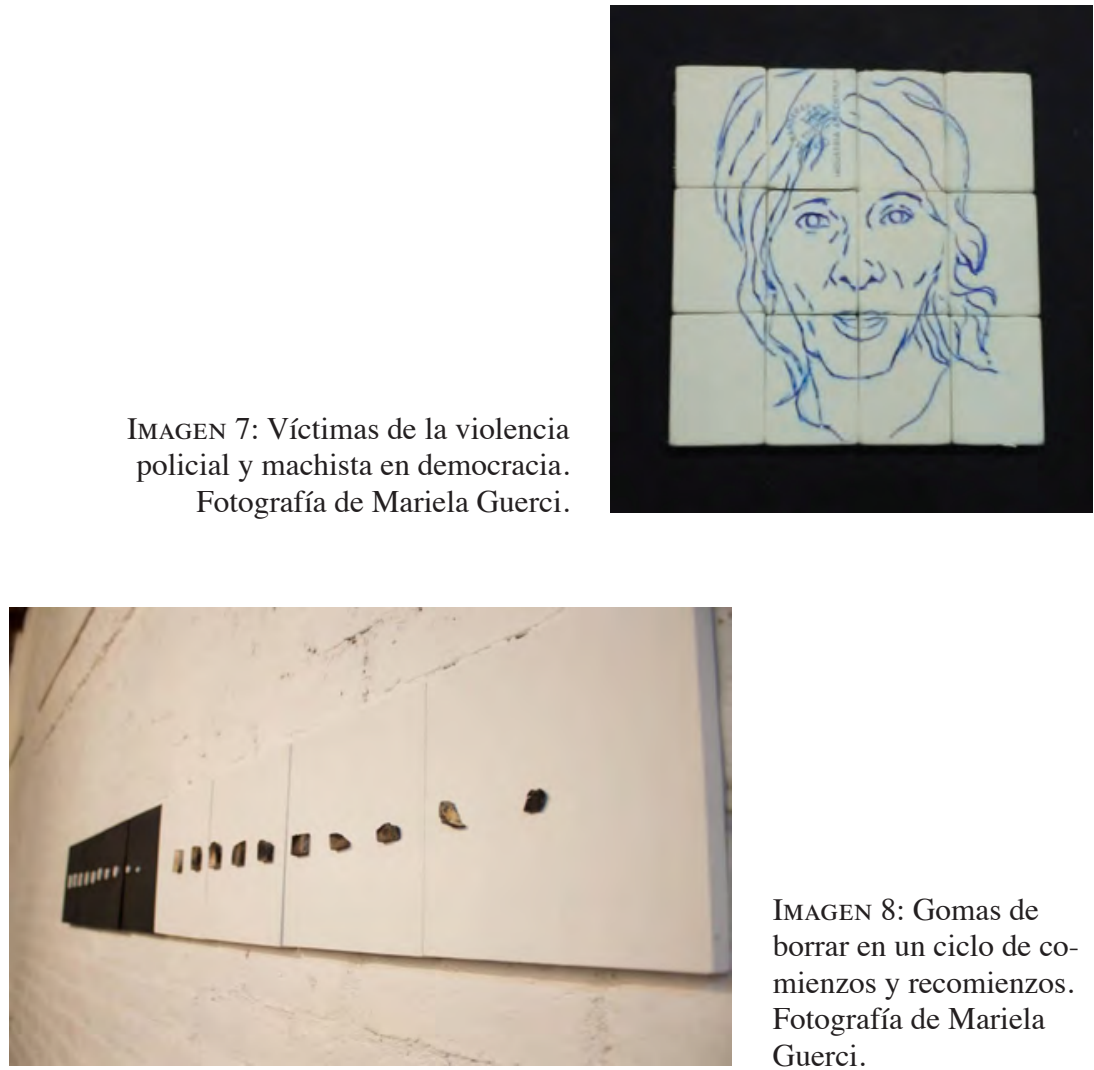

IMAGEN 8: Gomas de borrar en un ciclo de comienzos y recomienzos. Fotografía de Mariela Guerci. 
que apenas permitía adivinar la imagen subyacente, pero que podía ser develada a partir de la paulatina intervención de los espectadores (imágenes 9 y 10). Quitar esa capa, borrarla, permitía toparse con el frente de un edificio emblemático de la represión, que meses atrás había sido recuperado parcialmente como sitio de memoria.
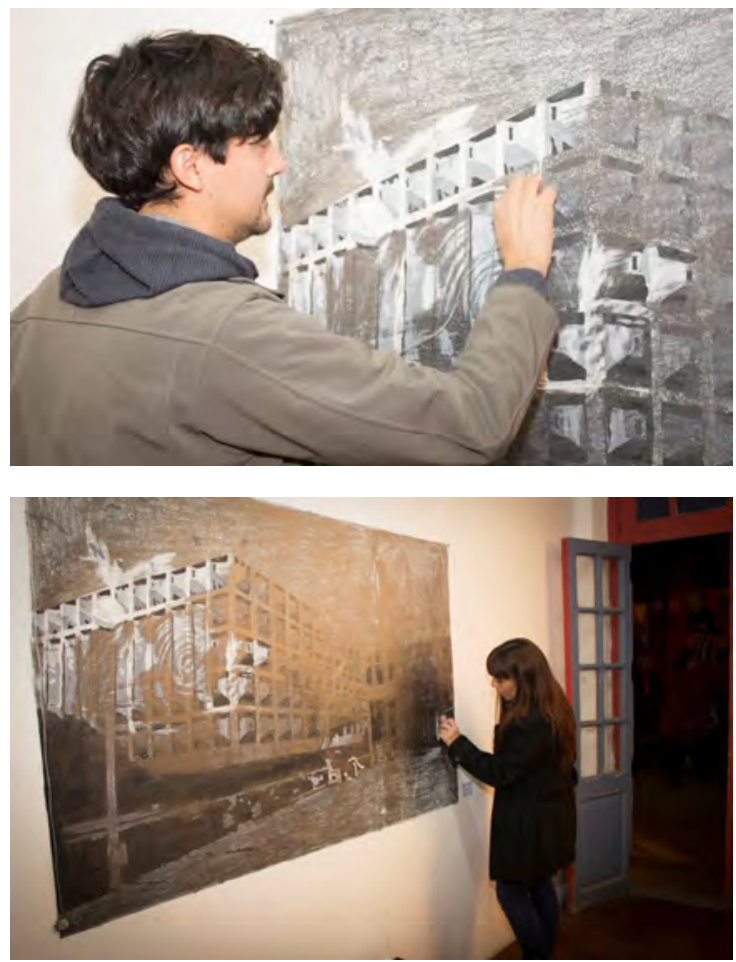

IMÁGENES 9 y 10: Develar lo oculto, primera instancia para resignificar un Centro Clandestino de Detención. Fotografía de Mariela Guerci.

\section{Aproximaciones a la obra de LAG}

desde una crítica de la memoria

Las obras anteriormente mencionadas poseen, según nuestra perspectiva, numerosos elementos para desplegar la crítica de la memoria que propone Richard. En principio, varios de los trabajos de La Araña que componen las muestras referidas apuestan por la intervención de los espectadores, tanto para dotarlos de sentidos posibles como para desentrañar 
lo que se presenta oculto, confuso. Resolver las sopas de letras, ubicar las palabras faltantes en una proclama estudiantil o quitar la película de grafito que recubre la reproducción del edificio del ex D2 son ejemplos de acciones en las obras expuestas que quedan a cargo del público.

Nelly Richard, en referencia al trabajo también colectivo del CADA (Chile), destaca que éste involucra “... obras cuyas estructuras operacionales se mantienen abiertas y cuyos materiales permanecen inconclusos, garantizando así la no-finitud del mensaje artístico, para que el espectador intervenga en la obra y complete su plural de significaciones heterogéneas y diseminadas" (Richard 2013: 17). En el caso de La Araña, la instancia de "completar" las obras - particularmente las de las proclamas estudiantiles de Ejercicio 1972 - se asienta fuertemente en las nociones, miradas y experiencias que los asistentes tengan del pasado reciente. Éste es un camino similar al que propusieron los artistas a los ex estudiantes, quienes tuvieron que elaborarlos con base en sus propios recursos experienciales.

No quedaba ningún ejemplar de esos documentos. Todos fueron secuestrados en allanamientos o quemados por los propios militantes, ante el peligro que significaban. No había quedado nada y de ahí surgió la idea de que lo escribieran según sus recuerdos, respetando el estilo y el lenguaje de la época cuando eran estudiantes. Lo que hicieron ellos es en parte lo que le pedimos que hiciera el público con los textos incompletos, es esa cuestión dinámica, de reconocer que la memoria no es un lugar al que podés recurrir y está todo dado... sino que la construís, implica un esfuerzo, implica estar activo (La Araña Galponera 2016c).

De este modo, se concretiza un proceso colectivo de memoria que se basa al mismo tiempo en el testimonio de los y las protagonistas, como en la apelación a las certezas construidas durante décadas de oposición al olvido. Los sentidos posibles de estas obras intervenidas por la ausencia de palabras no son infinitos; existen una realidad histórica, testigos, documentos a los cuales aferrarse para completar lo que se presentó desmembrado.

Por su parte, aquellas sopas de letras condicionan una participación de parte del espectador. En varios puntos diferentes a la mencionada y que más bien se asientan en la vocación de "descifrar silenciamientos, 
reservas y negaciones" desde una crítica de la memoria. Distinguir las letras que forman los nombres de los cómplices civiles de la represión, en una maraña de letras, resulta un mecanismo similar al que propusieron los escraches, ya que se busca denunciar la invisibilidad social de la que muchas veces gozaron los perpetradores.

Vale comentar en forma breve algunos hechos ocurridos durante la presentación de la muestra que refuerzan estos sentidos: la propuesta de encontrar esos nombres en la sopa de letras fue rápidamente aceptada por los primeros asistentes que se enfrentaron a la pizarra, algunos de ellos empleados de la propia facultad. No obstante, al desbordar las previsiones de los artistas, se anotó en el margen el nombre de una persona que habría tenido participación en la confección de las listas negras pero que no aparecía nombrado. Esa acción resultó incómoda para otros empleados (posiblemente porque la hija del mencionado trabaja actualmente allí), quienes borraron malamente el nombre agregado. Esas acciones de develación/borramiento hacen visible algunos límites de la revisión del pasado reciente; al menos, los existentes en varias instituciones académicas en las que pareciera promoverse el recuerdo respetuoso de las víctimas, pero sin cuestionar las responsabilidades de los victimarios. ${ }^{12}$ Podría decirse que está aceptado "recordar" pero no necesariamente "denunciar" y menos si esa denuncia tiene correlatos en un presente en el que los cómplices de la represión mutaron en cómplices del silencio.

A su vez, la inclusión de palabras claves, como los nombres de los y las estudiantes secuestrados y, sobre todo, de los objetivos políticos que los orientaron, permite, en conjunto, una asociación que no siempre fue posible ni es reflejada.

Entendemos que el proceso de memoria que se ha dado en esta última década ha aportado mucho pero es necesario dar otro paso. Los juicios a los genocidas, con su lento proceder, han juzgado y siguen juzgando a los hombres directamente vinculados a las fuerzas armadas. Esto nos obliga a pensar la dictadura como algo más amplio que la detención y desaparición de personas, pensarla hasta hoy, pensar sus consecuencias. Es

12 Estas afirmaciones también se basan en otra experiencia grupal de La Araña en la UNCUYO durante 2014. 
necesario analizar entonces qué fue lo que truncó, qué fue lo que mató antes que terminara de nacer (La Araña Galponera 2016d).

Las luchas contra la impunidad dictatorial se centraron primeramente en la denuncia del horror perpetrado, negado a la opinión pública durante años. En ese marco, las posibilidades de conocimiento y reivindicación de las luchas previas al golpe fueron posibles una vez lograda la impugnación del accionar represivo. La presencia de la palabra "revolución" aquí implica reconocer la existencia de proyectos políticos que desde entonces no pudieron volver a ser discutidos en esos términos. En efecto, una de las claves de lectura fundamentales para comprender los sesenta y los setenta como época (Gilman 2012: 36) se relaciona con la centralidad que alcanzó la idea de revolución. En primer lugar, como proyecto político transformador alcanzable en el mediano plazo, asociado, entonces, con distintas visiones del socialismo; pero también como concepto descriptivo de "ideas, conceptos, acontecimientos, prácticas, discursos, etc. que configuraron el perfil histórico particular del periodo en torno a la noción de cambio radical (costumbres, mentalidades, sexualidad, experiencias, regímenes políticos)" (Gilman 2012: 39).

Es un modo creativo de cuestionar los límites de pensar el pasado cercano desde el 24 de marzo de 1976, fecha trascendental que permite la vinculación con el terrorismo de Estado, pero no con quienes fueron señalados como enemigos públicos con valores contrarios a "nuestra civilización occidental y cristiana”. Identificar esos nombres entre la multitud de letras, ubicar palabras que fueron justificación para la represión pero que antes habían dado sentido a la vida de miles, es un ejercicio crítico de revisión del pasado que actualiza debates y reivindica luchas.

El triunfo conservador que significó la dictadura -inscrito en lo simbólico, pero basado en una realidad descarnada- también limitó, desde entonces, las posibilidades de una "unidad obrero-estudiantil", presente en la proclama "La UTN puede desaparecer" que fuera profusamente militada por el estudiantado. Hablamos, entonces, de obras que brindan materiales para reposicionar debates y proyectos revolucionarios silenciados por la represión y desjerarquizados en la posdictadura.

La reiterada apelación a la figura de Julio López en la obra de La Araña da cuenta, también, de otros aspectos que no sólo apuestan por 
la rememoración, sino que interpelan al conjunto social. ${ }^{13}$ Julio López, su nombre y su derrotero, chocan con la celebración de los avances en materia de juzgamiento a los represores e interpela al conjunto social desde su (repetida) desaparición forzada. Que su rostro sea borrable es tanto una realidad concreta como una advertencia. Es posible el olvido, es posible repetir el horror. Entonces, es necesario seguir haciendo posible la memoria.

Sin embargo, la batalla contra las reservas y los silenciamientos no sólo provienen del pasado dictatorial: la etapa contemporánea también incluye eventos que deben ser descifrados. Es lo que ocurre con los casos del llamado "gatillo fácil" (eufemismo que señala el accionar violento de la policía) y de trata de personas, que quedaron graficados en la muestra de 2016. Seguramente, aquí entran en juego, además de condicionamientos político-estatales, prejuicios y justificaciones solapadas que reactualizan aquel "algo habrán hecho" aplicado a los/as detenidos/as desaparecidos/as, ahora por motivaciones clasistas y machistas.

Si una crítica de la memoria debe "revisar y discutir las huellas del pasado archivado por la historia", la facultad de hacer visible el edificio del ex D2 a través de la acción de quitar la capa de grafito que lo ocultaba, es una base para esa tarea. ¿Qué tipo de huella es un edificio que sirvió como sitio para organizar los secuestros y perpetrar violaciones, torturas y asesinatos de cientos de personas? ¿Es posible resignificarlo en una huella que trascienda el horror sin negarlo?

Las obras expuestas no brindan ésas ni otras respuestas, en lugar de ello, hacen posible las preguntas; posibilidad que depende, otra vez, de la intervención activa del público sobre las mismas. Lo que se borra, también, son los límites entre artistas y observadores; entre emisores y receptores de perspectivas sobre el pasado. El activismo que se reclama no sólo es artístico o militante, es, sobre todo, colectivo.

13 La figura de Julio López está presente como tema en la obra de LAG desde su formación en 2007 y ha sido abordada cíclicamente a partir de distintas estrategias y localizaciones. 


\section{Conclusiones}

Se inició este recorrido a partir de la pregunta por la actualidad de los debates sobre arte y política en Argentina. Ubicar la crisis de 2001 como referencia de época para abordar los últimos años de un trayecto extenso y variado permite reconocer la importancia que el ciclo de protestas, iniciado a mediados de los noventa, posee en la emergencia de organizaciones políticas y colectivos de arte que dieron contenido a ese debate.

Entre los ejes que motivaron la participación colectiva en aquel entonces (desocupación, pobreza, impunidad...), la problemática de la memoria y la exigencia de justicia destacaron por sus antecedentes y por concretar el cruce entre nuevos perfiles militantes y experiencias de arte en acciones directas, como los escraches y las intervenciones recientes en las marchas del 24 de marzo, en repudio al golpe de Estado de 1976. No obstante, la concreción de ese cruce también se asentó en experiencias anteriores, tanto a nivel de la participación callejera como en obras que formaron parte del circuito artístico. Puede afirmarse, entonces, que la vitalidad del cruce entre arte y política logró sostenerse y actualizarse en vinculación con la temática de la memoria.

En ese marco, el trabajo de La Araña Galponera puede ser abordado a partir del reconocimiento de los puntos en común con el arte activista "de 2001", pero también a través de sus búsquedas y propuestas estéticas. Porque si una primera mirada hacia las producciones del colectivo permite reconocer un perfil callejero (en marchas, protestas, intervenciones en la vía pública) que lo vincula con la política; el análisis de los trabajos pensados para el circuito del arte local complementa y pone en tensión esa aproximación más evidente.

Una forma de lograr un análisis que no descuide ninguno de los flancos se expuso a partir de la propuesta de Nelly Richard respecto de una crítica de la memoria. Desde allí, se indagó en las estrategias estéticas del colectivo, a manera de producciones que buscan cuestionar los márgenes establecidos para perfilar visiones del pasado y miradas sobre el presente.

Se intentó mostrar, en definitiva, la necesidad de superar ciertas limitaciones para pensar la articulación entre arte y política en la etapa contemporánea, sin desconocer las dificultades que esto implica. En el caso 
de LAG, el acercamiento a lo político se concreta tanto por las características de producción (temas, materiales, circuitos), como por su forma organizativa (colectiva, autogestiva, en contacto directo agrupaciones y movimientos, pero también con otros artistas). Estos y otros aspectos forman parte de las condiciones de producción de un grupo de arte que plantea lecturas disonantes de la realidad en el ámbito que se encuentre.

La posibilidad de aproximarse a las dos últimas muestras del colectivo buscó ampliar la visibilidad de su obra - generalmente relacionada con la ocupación de la vía pública y la protesta social - y, además, señalar el modo en que las características de "lo político" también deben ser puestas en discusión. En efecto, las muestras reseñadas habilitan también la posibilidad de reconocer el modo en que la cuestión de la memoria y los derechos humanos es atravesada por procesos políticos dinámicos y cambiantes.

Si en Ejercicio 1972 (2015) una de las apuestas fue la incorporación de nombres y palabras claves para desmarcarse de una memoria previsible (respetuosa de las víctimas, pero muchas veces muda sobre proyectos militantes y victimarios), en Borrar, quemar, descubrir (2016), las sensaciones que priman parecen ser otras. Tal vez como señal de los distintos perfiles político-institucionales, la segunda muestra - ya durante la gestión macrista, plagada de "gestos" hacia los genocidas condenados y los sectores que representan - se asienta sobre la posibilidad del olvido, la extensión del concepto "desaparecidos" y la urgencia de una memoria activista.

Descifrar silenciamientos, preguntar por las omisiones, discutir las huellas. La Araña Galponera se instala en la discusión sobre lo que somos y lo que pudimos ser; ofrece elementos e imágenes en las que se materializan esos debates y se suma, con su práctica y producciones, a la discusión sobre las posibilidades de "un mundo mejor", lo que antes del último golpe de Estado se llamaba revolución.

\section{Bibliografía}

FeIRSTEIn, Daniel (2012). "Memoria, trauma y trabajo de elaboración. Una mirada desde Sigmund Freud", en Memorias y representaciones. Sobre la 
elaboración del genocidio. Buenos Aires, Fondo de Cultura Económica: 61-89.

Felshin, Nina. (ed.) (1994). But is it art? The spirit of art as activism. Seattle, By Press.

Gilman, Claudia (2012). Entre la pluma y el fusil; debates y dilemas del escritor revolucionario en América Latina. Buenos Aires, Siglo XXI.

Giunta, Andrea (2009). Poscrisis; arte argentino después de 2001. Buenos Aires, Siglo XXI.

GonZÁLEZ, Florencia Eva (2013). Desajustes. Sobre arte y política en Argentina. Buenos Aires, Paradiso.

Hall, Stuart (1996). “¿Quién necesita identidad?” en Cuestiones de identidad cultural. Buenos Aires, Amorrortu: 13-39.

La Araña Galponera (2015). Ejercicio 1972. Catálogo de la muestra. Mendoza, s.e.

- (2016a). Borrar, quemar, descubrir. Catálogo de la muestra. Mendoza, s.e.

Longoni, Ana y Gustavo Bruzzone (comps.) (2008). El Siluetazo. Buenos Aires: Adriana Hidalgo editora.

Longoni, Ana (2013). "Encrucijadas del arte activista en Argentina”, en Lorena Méndez, Brian Whitener y Fernando Fuentes (eds.), De gente común. Prácticas estéticas y rebeldía social. México, Universidad Autónoma de la Ciudad de México: 89-123.

Richard, Nelly (2010). Crítica de la memoria (1990-2010). Santiago de Chile, Universidad Diego Portales.

- (2013). "Márgenes e instituciones; la Escena de Avanzada", en Nelly Richard, Fracturas de la memoria; arte y pensamiento crítico. Buenos Aires, Siglo XXI: 13-28.

Otras fuentes

La Araña Galponera (2016b, marzo). Entrevista por el autor.

- (2016c, julio). Entrevista por el autor. 